\title{
World market for nanomaterials: structure and trends
}

\author{
Elena Inshakova ${ }^{1, *}$ and Oleg Inshakov ${ }^{1}$ \\ ${ }^{1}$ Volgograd State University, Department of International and Regional Economy, 400062 Volgograd, Russia
}

\begin{abstract}
Modern nanomaterials as well as the other advanced materials are aimed at scaled production application due to their unique physical and chemicals properties and the improved performance of final products, therefore at enforcing technological and economic progress of the countries. The article focuses on current state and key indicators of development of the world nanomaterials market, its key drivers and restraints, modern structure, emerging trends and prospects. Selected foreign and Russian databases, providing information on nanomaterials, which are applied in industrial production, and final products manufactured with the use of nanomaterials or nanotechnology are examined in the article. The authors come to the conclusion that information asymmetry, heterogeneity and even inconsistency of the information in the databases exist, thus making it difficult to obtain relevant business information both for manufacturers and consumers. These factors hinder development of nanoindustry in the Russian Federation, as well as national and regional markets for nano-enabled consumer products.
\end{abstract}

\section{Dynamics and trends of the world nanomaterials market}

The development and industrial application of innovative advanced materials is imperative for technological and economic progress of a country. Nanomaterials, with at least one external dimension in the size range of approximately 1 to 100 nanometers, due to their unique physical and chemicals properties resulting in improved performance and qualitative characteristics of final products and ample opportunities of applying in numerous end-user industries are widely used in energy storage, construction, electronics, aerospace, defense, production of sporting and other consumer goods, etc.

The modern drivers of the world nanomaterials market are as follows: increase in the market penetration of existing materials, decrease in the prices of nanomaterials, improving materials' properties, expending R\&D activities related to the new materials, increase in public and private expenditure towards nanotechnology research, growing support of the government institutions, rapid new materials and applications' development [1-3], effective functioning the partnerships and strategic alliances of domestic and foreign companies and organizations, increasing number and collaboration among industry players including growing international research and production cooperation in nanotechnology industry.

The factors mentioned above have had a positive impact on the development of the world nanomaterials market and have resulted in the steady growth of the key market indicators. As to the conservative estimate by Mordor Intelligence, the global nanomaterials market was valued at about USD 4.1 billion in 2015 and expected to reach USD 11.3 billion by 2020, at a compound annual growth rate (CAGR) of over $22 \%$ during the forecast period 2017-2022 [4].

On the contrary, the new report by Allied Market Research optimistically projects the global nanomaterials market to reach more than USD 55.0 billion by 2022 from USD 14.7 billion in 2015, growing at a CAGR of $20.7 \%$ during this time period [5], while Deloitte Touche Tohmatsu Limited experts are much less optimistic declaring only $15.5 \%$ CAGR of global nanomaterials market in 2012-2019 [6, p. 4].

The pessimistic and optimistic views on the positive dynamics and prospects of the global value of nanomaterials have been presented at figures $1[3,4]$ and $2[2,5]$ below.



Fig. 1. Global value of nanomaterials, pessimistic view (USD billion).

\footnotetext{
* Corresponding author: inshakovae@mail.ru
} 


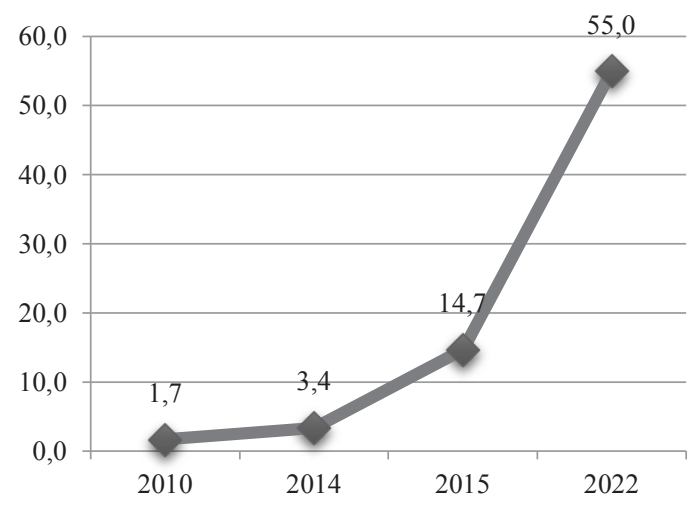

Fig. 2. Global value of nanomaterials, optimistic view (USD billion).

The European nanomaterials market generated revenue of more than USD 2.5 billion in 2015 and is expected to reach USD 9.1 billion by 2022 with a CAGR of $20.0 \%$ during 2016-2022 [7].

No matter what scenario of development of the global nanomaterials market has been taken into consideration, the fact is that it is expected to grow at a faster CAGR than the global nanotechnology market as a whole. The latter is projected by the RNCOS analysts to grow at a CAGR of around $17 \%$ during the forecasted period of 2017-2024 [8].

Major factors restraining development of the global nanomaterials market are: the growing concerns over their impact on human health and the environment (toxicity of nanomaterials themselves, presence of toxic solvents, release of hazardous intermediate compounds, toxicity of wastes resulted from nanomaterials' processing or manufacturing); stringent requirements in the frameworks of the government environmental regulation.

For example, the International Agency for Research on Cancer (IARC) states that oral exposure to titanium dioxide (known as E171 and presented in sweets, chocolate products, toothpaste, pharmaceutical products, etc.) becomes a factor of initiating and promoting early stages of colorectal carcinogenesis for humans.

The most important regulatory bodies related to nanomaterials in the US and the EU are:

- The United States Environmental Protection Agency (EPA), setting national standards of environmental protection and enforcing regulations in this sphere (The Toxic Substances Control Act, TSCA; Resource Conservation and Recovery Act, RCRA; etc.);

- The European Chemicals Agency (ECHA), facilitating the implementation of the obligations under the crucial regulations: Regulation (EC) No 1907/2006 of the European Parliament and of the Council on the Registration, Evaluation, Authorisation and Restriction of Chemicals (REACH); the Regulation (EC) No 1272/2008 on the classification, labelling and packaging of substances and mixtures (CLP Regulation); The Biocidal Product Regulation (BPR, Regulation (EU) 528/2012), and others.

In China, for example, it is the Ministry of Industry and Information Technology (MIIT), which has published new guidelines for industries that create new materials, such as graphene. The guidelines had been jointly developed by the MIIT, the National Development and Reform Commission, the Ministry of Science and Technology and the Ministry of Finance.

It should be mentioned the emerging trends in the global nanomaterials industry: growing demand for high strength and durable structural materials, new material development and product design, new and emerging market applications, falling nanomaterials' prices, enlarging the scale of the market due to the growing activities of the existing suppliers and the new entrants, as well as the increase in government support and $R \& D$ funding.

\section{Structure of the world nanomaterials market by type of material, region and application}

By material type, one can find several approaches to segmenting the global market for nanomaterials: a) carbon based, metal and non-metal oxides, metals, dendrimers, nanoclay, and nanocellulose [7]; b) nanoparticles, nano-fibers, nano-tubes, nano-clays and nanowires [4]; c) carbon black, carbon nanotubes, graphene, fullerene, nanofibers; silica fumes; clay; metal/alloys; ceramics [9]; and some others.

Allied Market Research experts team states that metal and non-metal oxide-based nanomaterials are the most widely applied in the industrial production with expected growth at a CAGR of $20.7 \%$ from 2016 to 2022 [5]. About $25 \%$ of the nanoproducts introduced into the markets are incorporated by titanium dioxide, silver, or silicon dioxide nanoparticles [14, p. 65] Titanium dioxide and silicon dioxide are mostly consumed metal and non-metal oxidebased nanomaterials. Consumption of silicon dioxide was 198 kilo tons in 2015 and is projected to reach 786 kilo ton by 2022 , at a CAGR of $21.8 \%$.

Nano silver due to its antibacterial and antimicrobial properties is among the most popular nanomaterials used in manufacturing consumer products by the companies in numerous industries, mostly electronics, IT, healthcare and beauty, textiles ( $20 \%$ of the world silver nanoparticles market).

Silver nanoparticles are considered by the Global Market Insights Inc. analysts to be the most commercialized nanoparticles, accounting for over 50\% of the global nanomaterial consumer products in 2015 [10] with expectation of growth of the market at a CAGR of nearly $13 \%$ in 2016-2024 [11]. Prior areas of silver nanoparticles application are healthcare and life sciences, food and beverages packaging industry (improved packaging and active packaging), electronics and IT sector.

The global markets for nanoclay and nanocellulose also demonstrate stable growth of the indicators based on the enlarging spheres of their industrial application [5]. According to the Transparency Market Research (TMR) forecasts, the market revenue of nanoclay is expected to grow at a CAGR of $24.9 \%$, and of nanocellulose market $19 \%$ until at list $2020[12,13]$. 
The prospects of selected nanomaterials markets have been summarized in the table 1 .

Table 1. Selected nanomaterials markets.

\begin{tabular}{|c|c|c|c|}
\hline $\begin{array}{c}\text { Selected } \\
\text { nanomaterials } \\
\text { market }\end{array}$ & $\begin{array}{c}\text { Global } \\
\text { market } \\
\text { revenue } \\
\text { by } 2016, \\
\text { USD } \\
\text { billion }\end{array}$ & $\begin{array}{c}\text { Expected } \\
\text { global } \\
\text { market } \\
\text { revenue by } \\
\text { 2021, USD } \\
\text { billion }\end{array}$ & $\begin{array}{c}\text { Expected } \\
\text { CAGR in } \\
2016- \\
2021, \\
\text { percent }\end{array}$ \\
\hline $\begin{array}{l}\text { Silver } \\
\text { nanoparticles }\end{array}$ & 1.1 & 3.0 & 13 \\
\hline Nanoclays & 0,7 & 2,1 & 24,9 \\
\hline Nanocomposites & 1.6 & 5.3 & 26.7 \\
\hline Quantum dots & 0.61 & 3.4 & 41.3 \\
\hline Nanofibers & 0.39 & 2.0 & 38.6 \\
\hline $\begin{array}{l}\text { Advanced \& } \\
\text { nanoscale } \\
\text { ceramic powders }\end{array}$ & 14.6 & 22.3 & 8.9 \\
\hline
\end{tabular}

Source: Silver Nanoparticles Market Size (2017); Global Silver Nanoparticles Market Trends (2017); Nanocellulose Market (2015); Nanoclay market (2016); Nanomaterials Market - Global Opportunity Analysis (2016).

Dynamics of the global nanomaterials demand by regions and sectors can be seen at figure $3[2,5]$.

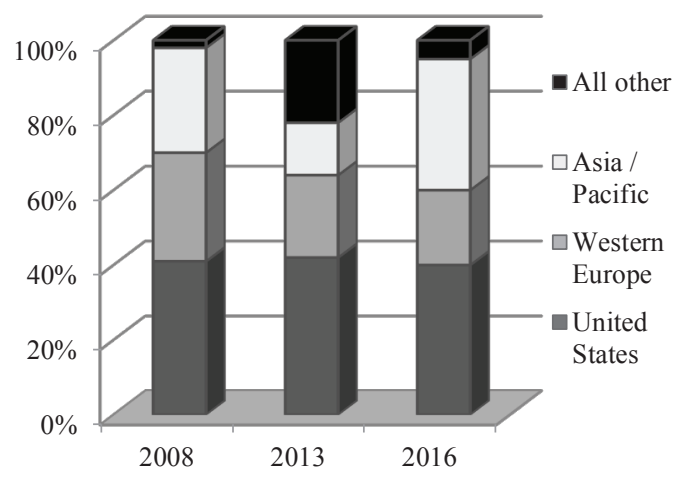

Fig. 3. Global demand for nanomaterials by regions (percentage).

In 2014, the US and Japan accounted for over a half of world demand for nanomaterials, while the EU countries and two high-income East-Asian countries, Taiwan and South Korea, represented an additional 34\%.

The US led the global nanomaterials market in 2015 and is projected to keep this leading position until 2022 with the nanomaterials market revenue growing at a CAGR of $20.5 \%$.

In 2016, North America and Asia-Pacific collectively accounted for $3 / 4$ of the world demand for nanomaterials and are expected to maintain leadership throughout the examining period. At the same time, the highest CAGR of nanomaterials market revenues is projected in AsiaPacific countries (21.4\%), backed by North America and Europe.

Among the Asian countries the fastest growth in demand for nanomaterials is forecasted for China and India, while China is predicted to become the second largest market for nanomaterials following the U.S. with over $11 \%$ share of the global demand by 2022 .
On the basis of applications, one should identify the following segments in the structure of the global nanomaterials market: electrical and electronics industry, construction, energy storage, healthcare, consumer goods, packaging, transportation, aerospace, water filtration, and others.

Nevertheless, the Allied Market Research analysts point out the industries with the highest opportunities for applying modern nanomaterials in production of the final goods: aerospace, sporting goods, automotive, energy storage, electronics and defence industries [7]. The electronics industry is expected to account for the highest share in the market (about 30\%), while the aerospace sector - the fastest growing sector during the forecast period due to the increasing usage of nanometals, polymer nanocomposites and anti-corrosion coatings in the aircraft manufacturing.

\section{Nanomaterials development and production: problems of representation in the databases}

The development of applied research in the field of nanomaterials and nanotechnology can be represented by the positive dynamics of the patent activity of countries, that is by the growing number of patents issued by international and regional (see tables 2 and 3 ) registration systems.

The generalised information in this field one can get in the open access, for example, at the website of StatNano project, which has been launched with the support of Iran Nanotechnology Initiative Council (INIC).

In terms of the quantity of nanotechnology patents registered in the European Patent Office (EPO) in 2016, as to the StatNano database, Russia has been on the 29th place among 56 countries, while in the United States Patent and Trademark Office (USPTO) - has shared 21st place with Austria and Denmark among 59 countries under consideration [14, p. 36-37].

Table 2. Nanotechnology patents in EPO by countries (units).

\begin{tabular}{|c|c|c|c|c|c|c|}
\hline Rank & Country & $\mathbf{2 0 1 2}$ & $\mathbf{2 0 1 3}$ & $\mathbf{2 0 1 4}$ & $\mathbf{2 0 1 5}$ & $\mathbf{2 0 1 6}$ \\
\hline 1 & USA & 306 & 350 & 361 & 421 & 577 \\
\hline 2 & Germany & 208 & 243 & 206 & 229 & 289 \\
\hline 3 & France & 128 & 145 & 140 & 152 & 208 \\
\hline 4 & Japan & 133 & 134 & 141 & 131 & 188 \\
\hline 5 & $\begin{array}{c}\text { South } \\
\text { Korea }\end{array}$ & 49 & 55 & 73 & 52 & 105 \\
\hline 6 & UK & 45 & 38 & 45 & 45 & 81 \\
\hline 7 & Switzerland & 37 & 47 & 63 & 48 & 75 \\
\hline 8 & Netherlands & 37 & 45 & 38 & 43 & 71 \\
\hline 9 & China & 15 & 16 & 14 & 28 & 59 \\
\hline 10 & Italy & 43 & 37 & 29 & 47 & 49 \\
\hline$\ldots$ & $\ldots$ & $\ldots$ & $\ldots$ & $\ldots$ & $\ldots$ & $\ldots$ \\
\hline 29 & Russia & 1 & 0 & 4 & 3 & 6 \\
\hline & World & 1,133 & 1,255 & 1,289 & 1,415 & 2,006 \\
\hline
\end{tabular}

Source: StatNano (2017). 
Table 3. Nanotechnology patents in USPTO by countries (units).

\begin{tabular}{|c|c|c|c|c|c|c|}
\hline Rank & Country & $\mathbf{2 0 1 2}$ & $\mathbf{2 0 1 3}$ & $\mathbf{2 0 1 4}$ & $\mathbf{2 0 1 5}$ & $\mathbf{2 0 1 6}$ \\
\hline 1 & USA & 3,041 & 3,615 & 4,414 & 4,365 & 4,316 \\
\hline 2 & $\begin{array}{c}\text { South } \\
\text { Korea }\end{array}$ & 430 & 501 & 667 & 839 & 914 \\
\hline 3 & Japan & 526 & 587 & 889 & 902 & 819 \\
\hline 4 & Taiwan & 407 & 425 & 551 & 500 & 514 \\
\hline 5 & China & 225 & 270 & 357 & 393 & 416 \\
\hline 6 & Germany & 205 & 248 & 496 & 307 & 301 \\
\hline 7 & France & 140 & 176 & 347 & 242 & 210 \\
\hline 8 & $\begin{array}{c}\text { Netherla } \\
\text { nds }\end{array}$ & 103 & 115 & 155 & 156 & 136 \\
\hline 9 & UK & 60 & 87 & 145 & 109 & 123 \\
\hline 10 & Canada & 82 & 85 & 127 & 109 & 106 \\
\hline$\cdots$ & $\cdots$ & $\cdots$ & $\cdots$ & $\cdots$ & $\cdots$ & $\cdots$ \\
\hline 21 & Russia & 4 & 4 & 11 & 8 & 12 \\
\hline & World & 5,342 & 6,354 & 8,681 & 8,588 & 8,484 \\
\hline
\end{tabular}

Source: StatNano (2017).

The actual data on the produced nanomaterials, manufactures and products with the use of nanomaterials and nanotechnology are available at the websites of the Nanowerk Nanomaterial Database ${ }^{\mathrm{TM}}$, the StatNano Nanotechnology Products Database (NPD), the Netherlands NANO Supermarket, the DaNa2.0 (Data and Knowledge on Nanomaterials) in Germany, and some others abroad, as well as the Unified Computer Database on Nanomaterials and Nanotechnologies Used in the Russian Federation (website http://web.ion.ru/GM_1/GM.aspx), and the profiled registries of the Startbase - System of Supporting and Promoting Innovation (website https://www.startbase.ru/registries/), which are held by the Fund for Infrastructure and Educational Programs (FIEP), the member of RUSNANO group.

The Nanowerk Nano catalog contains 3883 nanomaterials, including 691 nanotubes, 2617 nanoparticles, 114 graphene items, 231 quantum dots, 99 fullerenes, 83 nanowires and 48 nanofibres from more than 150 suppliers worldwide. By the end of March 2017 the StatNano NPD has monitored 79 nanomaterials produced by 1188 manufacturers in 52 countries and applied by 13 industries in 642 product types.

Among 1574 items registered in the nanomaterials section of the Unified Computer Database on Nanomaterials and Nanotechnologies Used in the Russian Federation less than $7 \%$ are evident nanomaterials (including nanopowders, nanoparticles, nanocoatings, nanoclays, nanocomposites, etc.) while the rest of items are the final products produced with applying nanomaterials or nanotechnology. The similar problem is typical for the content of the nanomaterials section in the Startbase Nanotechnology Product Registry, for the DaNa2.0, and the NANO Supermarket.

Thus, the fact is that the majority of existing foreign and Russian databases under consideration represent asymmetry, heterogeneity and even inconsistency of the information, because they list both nanomaterials, which are applied in industrial production, and final products, which are manufactured with the use of nanomaterials or nanotechnology. This makes it difficult to obtain relevant business information for manufacturers and consumers, and, therefore, hinders consolidation of nanoindustry in the Russian Federation, as well as development of national and regional markets for nano-enabled consumer products.

This material is based upon work supported by the Russian Foundation for Humanities under project No. 16-02-00591 "State policy of the RF in the sphere of nanoindustry in an unfavorable external environment".

\section{References}

1. Nanotechnology Market Outlook 2020 (RNCOS EServices Pvt. Ltd., Noida, Uttar Pradesh, 2015)

2. World Nanomaterials: Industry Study with Forecasts for 2016 \& 2021. Study \#2871 (The Freedonia Group, Cleveland, OH, 2012)

3. Nanotechnology Update: U.S. Leads in Government Spending Amidst Increased Spending Across Asia (Lux Research Inc., Boston, MA, 2015)

4. Nanomaterials Market - Global Trends, Investment Analysis and Future Scope to 2022 (Mordor Intelligence, Hyderabad, Telangana, March 2017)

5. Nanomaterials Market - Global Opportunity Analysis and Industry Forecast, 2014-2022 (Allied Market Research, September 2016)

6. D. Dickson, Advanced Manufacturing in a Highly Connected World (Deloitte Touche Tohmatsu Limited, 2015)

7. Europe Nanomaterials Market by Type of Material, by End User - Opportunity Analysis and Industry Forecast, 2014-2022 (Allied Market Research, October 2016)

8. Global Nanotechnology Market Outlook 2024 (RNCOS E-Services Pvt. Ltd., Noida, Uttar Pradesh, 2016)

9. T. Abraham, Nanotechnology and Nano Materials: Types, Current/Emerging Applications and Global Markets (Innovative Research and Products, Inc., 2011)

10. Silver Nanoparticles Market Size by Application, Industry Analysis Report, Regional Outlook, Growth Potential, Price Trends, Competitive Market Share \& Forecast, 2016-2024 (Global Market Insights Inc., January 2017)

11. Global Silver Nanoparticles Market Trends 2017 Industry Report Forecast, 2016-2024 (Fractovia.org, Ocean View, Delaware, 2017)

12. Nanocellulose Market - Global Industry Analysis, Forecast 2014-2020 (Transparency Market Research, 2015) 
13. Nanoclay market - Global Industry analysis, Size, Share, Growth, Trends and Forecast 2015-2023 (Transparency Market Research, 2016)
14. StatNano 2016-Status of Nano-science, Technology and Innovation (Statnano Publications, 2017 